\title{
A3 NATURAL AUTOANTIBODIES REACTIVE TO GLYCOSAMINOGLYCANS ARE DISEASE STATE MARKERS IN RHEUMATOID ARTHRITIS AND ARE ASSOCIATED WITH HLA
}

B György, L Tóthfalusi, G Nagy, M Pásztói, P Géher, A Polgár, B Rojkovich, I Ujfalussy, P Misják, A Koncz, E Pozsonyi, G Füst, A Falus, E I Buzás Semmelweis University, Hungary

10.1136/ard.2010.129577c

Introduction Although natural autoantibodies make up the majority of circulating immunoglobulins, they have received little attention lately. This study examined systematic antibodies (Abs) reactive to glycosaminoglycans (GAGs), the carbohydrate components of proteoglycans that are released in large amounts from degrading cartilage.

Methods To measure Abs reactive to six different types of GAGs, a specialised ELISA was used in which the carbohydrates were covalently linked to the plastic surface through a $2 \mathrm{~nm}$ spacer. Sera from rheumatoid arthritis patients $(\mathrm{n}=6)$, umbilical cord serum samples $(n=1)$ and adult controls $(n=4)$ were studied. In order to explore crossreactivity with microbial antigens, bacterial peptidoglycans and fungal polysaccharides were used. Sera and synovial fluid samples were also tested using a GlycoChip carbohydrate array to characterise individual carbohydrate recognition patterns.

The authors followed a multistep statistical screening strategy for screening GAG-reactive Abs as predictive disease markers. The authors determined the concentrations anti chondroitin sulphate $\mathrm{C}$ of 78 healthy individuals and in their 86 children. In case of all the 164 individuals alleles of several polymorphisms were determined in class II (HLA-DQ, -DR), class III (AGER429T $\rightarrow$ C, HSP70 -2 1267A $\rightarrow$ G, TNF308G $\rightarrow$ A, CFB S/F, copy number of the C4A and $\mathrm{C} 4 \mathrm{~B}$ genes) and class I (HLA-A, -B) regions of the major histocompatibility complex (MHC).

Results While anti-GAG Abs were absent in the umbilical cord sera, they were readily detectable in adult controls and were significantly elevated in patients with rheumatoid arthritis $(p<0.001)$. Anti-GAG Abs showed significant crossreactivity among different types of GAGs. They also reacted with bacterial peptidoglycans and fungal polysaccharides.

Interestingly, anti-chondroitin sulphate $\mathrm{C} \operatorname{Ig} \mathrm{M} \mathrm{Ab}$ levels showed inverse correlation both with the Disease Activity Score 28 scores and $C$ reactive protein levels in rheumatoid arthritis. Furthermore, the authors found significant differences in the serum levels of the IgM type anti-chondroitin sulphate $\mathrm{C}$ Abs between carriers and non-carriers of the HLADR2 (15 and 16) antigens. In both cases the Ab concentrations were higher in the HLA-DR15 carriers $(p=0.002$ and $p=0.008$, respectively) and lower in DR16 carriers ( $p=0.029$ and $p=0.049$, respectively) than in the non-carriers.

Conclusion The highly abundant and cross-reactive, GAG specific natural autoantibodies in serum may serve as novel diseasestate markers in patients with rheumatoid arthritis. Also, our observations indicate that not only adaptive immune response but also natural autoantibody pattern, as a part of innate immune response, is influenced by the $\mathrm{MHC}$ allele composition. 